\title{
Neural network realization of sensorimotor space organization using predictability and decorrelation
} Madhusudhana Rao*, Daniel Weiller, Robert Märtin and Peter König

Address: Institute of Cognitive Science, University of Osnabrück, Osnabrück, 49080, Germany

Email: Madhusudhana Rao* - rmadhusu@uos.de

* Corresponding author

from Eighteenth Annual Computational Neuroscience Meeting: CNS*2009

Berlin, Germany. 18-23 July 2009

Published: 13 July 2009

BMC Neuroscience 2009, 10(Suppl I):PI45 doi:I0.I I86/I47I-2202-I0-SI-PI45

This abstract is available from: http://www.biomedcentral.com/I47I-2202/I0/SI/PI45

(c) 2009 Rao et al; licensee BioMed Central Ltd.

\section{Introduction}

Different coding principles like stability have been successfully applied to passive sensory stimuli to capture sensory representation of neurons [1]. It has become obvious later that the agent's behavioral repertoire has a crucial impact on the formation of the sensory representation and thus highlights the importance of the sensorimotor space. A heuristic rule-based investigation [2] demonstrates that optimizing the predictability in sensorimotor space of foraging agent leads to the emergence of place fields. The present work implements this principle in a biologically plausible neural-network architecture.

\section{Methods}

We use a virtual robot exploring environments with different exploration parameters. Its behavior is captured in a transition matrix, quantifying the probability to receive certain sensory signals as a consequence of previous sensory signals and the chosen behavior. Next, we implemented predictability and decorrelation in a Hebbian framework. After learning, response properties of neurons are quantified and compared to alternative adaptation scheme [2].

\section{Results}

Figure 1 represents the initial assumed representation of a circular environment. This was taken from an intermediate stage of the heuristic rule based implementation [2]. Figure 2 obtained after learning on the neural network through 2000 timesteps (actions) by the robot in the envi-

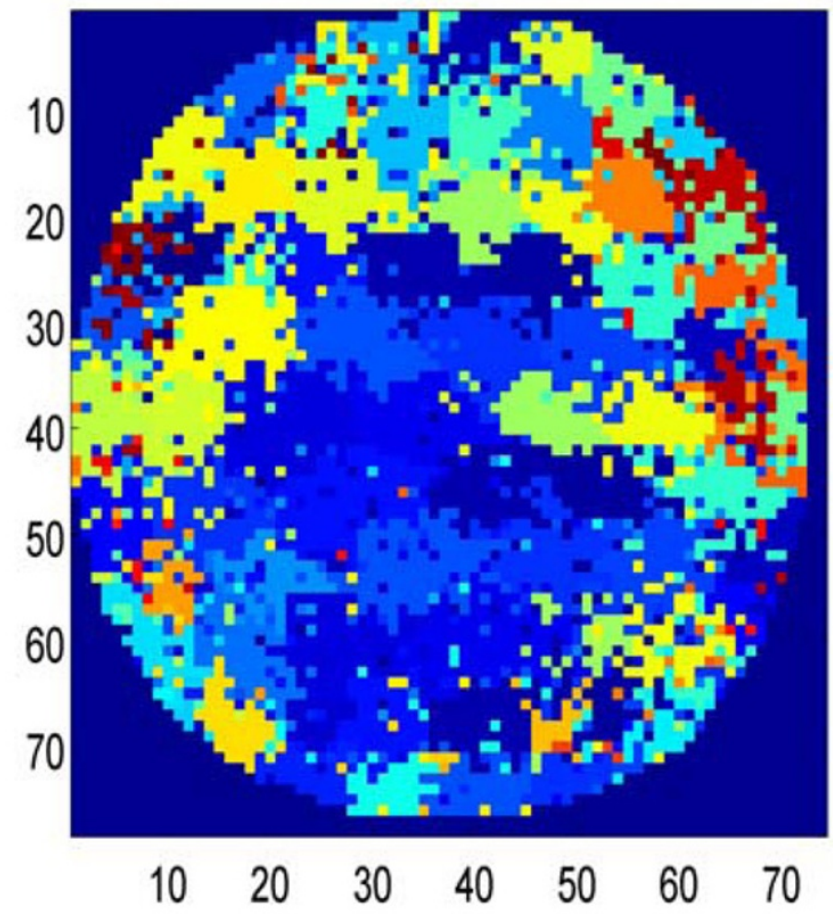

Figure I

Initial assumed representation of a circular environment. 


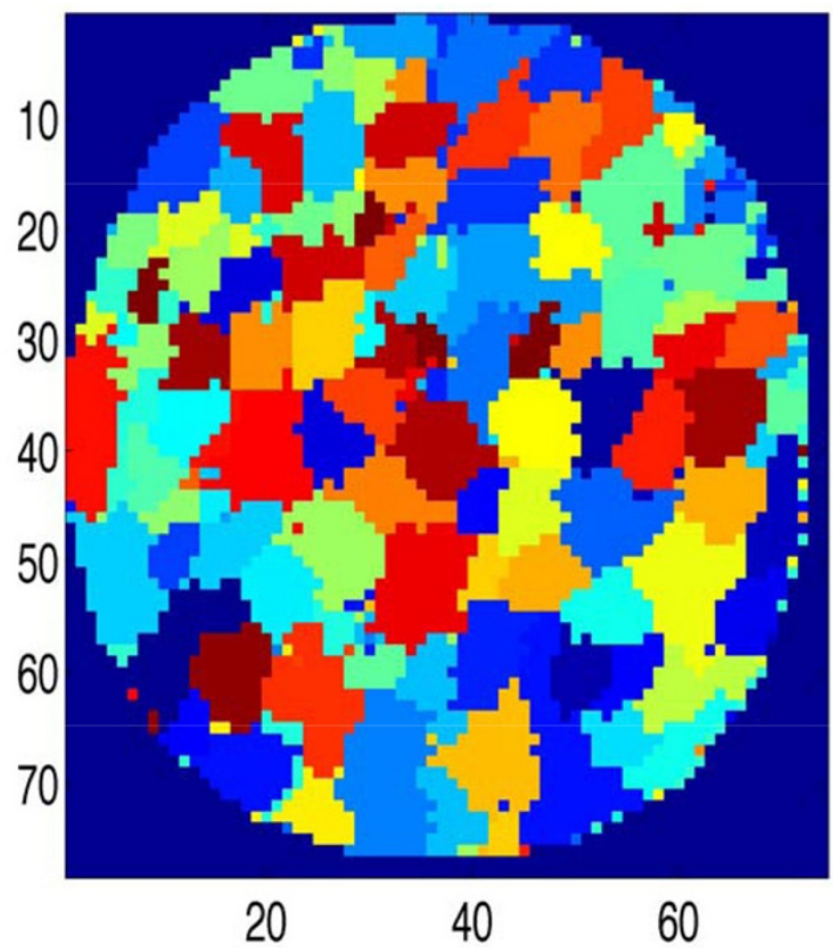

Figure 2

Sensorimotor representation after 2000 steps of learning.

ronment. The learning leads to compact states that are similar to place fields. The network learns quickly and converges to a stable state.

\section{Discussion}

Although predictability appears mathematically complex, it is possible to implement it in a biologically plausible neural network. The performance is as good as the heuristic rule based algorithm in terms of convergence. Therefore, predictability holds the promise to be a general principle in cortical processing.

\section{Acknowledgements}

The European Commission for the SF project; contract number FP7-ICT$217 \mid 48-S F$.

The authors and contributors of IQR, particularly Ulysses Bernardet, UPF, Barcelona.

Joao Hespanha, for providing Matlab function for graph partitioning. http:// www.ece.ucsb.edu/ hespanha.

\section{References}

I. Wyss R, König P, Verschure PF: A model of the ventral visual system based on temporal stability and local memory. PLoS Biology 2006, 4:el 20.

2. Märtin R, Weiller D, Dähne S, Engel AK, König P: Sensory space representations based on motor capabilities. Eighth Göttingen Meeting of the German Neuroscience Society 2009.
Publish with Biomed Central and every scientist can read your work free of charge

"BioMed Central will be the most significant development for disseminating the results of biomedical research in our lifetime. "

Sir Paul Nurse, Cancer Research UK

Your research papers will be:

- available free of charge to the entire biomedical community

- peer reviewed and published immediately upon acceptance

- cited in PubMed and archived on PubMed Central

- yours - you keep the copyright
BiolMedcentral 